\section{Taxonomy in Distress}

Sir,-Your obituary notice of A. W. Stelfox (Nature, 238, 175 ; 1972) highlights a problem which he felt acutely: the neglect of insect taxonomy. For British workers the departure of his unique collection to Washington is a loss paralleled only by that of the Curtis Collection in the nineteenth century. Stelfox was for some 25 years my valued teacher and friend, and I often worked on portions of the collection. I knew that the time spent on amassing it had prevented his working it out as he wished and that no institution in this country could guarantee to do so. As an insect taxonomist myself, I understood his keen disappointment.

I, too, am seriously concerned about the outlook for insect taxonomy in Britain. In earlier days much was done by gifted amateurs having private means. Nowadays the burden rests mainly on the professional. The British Museum (Natural History), the Commonwealth Institute of Entomology, and the universities, have all made taxonomic revisions of certain groups. However, the staff of the two former are so occupied with the demands of a world collection and routine identifications, that little time remains for research on the fundamental British and other European material. Taxonomists are rare in our universities, where the subject is generally neglected, and are burdened with ever-increasing teaching duties. Some amateurs continue to produce valuable revisions. All this, however, is a drop in the ocean. For example, the taxonomy of several huge groups of parasitic Hymenoptera, so important economically, is deplorably out of date, in some cases by a century or more. Notable progress made just after the Second World War is clearly not being maintained. Several specialists are due to retire and there are too few recruits. This, it must be emphasized, is not just an academic problem. Ecological studies, vital to our study of the environment, are futile unless based on sound taxonomy.

Only a large scale, carefully organized scheme to supplement existing efforts, perhaps supported by our research councils, will save the taxonomic situation. Taxonomy has too long been the Cinderella of science. We owe a duty to our illustrious pioneers to see that this does not continue.

Yours faithfully,

M. W. R. DE V. GRaham

Hope Department of Entomology,

University Museum, Oxford

\section{Pesticides and Peregrines}

SIR,-There is more than propaganda to justify the belief that the persistent pesticides led to striking declines in the peregrine falcon in many countries (Nature, 238, $116 ;$ 1972). The evidence has been marshalled in detail by Hickey ${ }^{1}$ and more recently, with special reference to their sub-lethal effects on fertility, by Ratcliffe $^{2}$. Mr Gunn quoted the report to the Wilson Committee ${ }^{3}$; it is a pity that he did not also mention their finding in an earlier paragraph, when discussing the very marked decline in the peregrine falcon and sparrowhawk and the decreases in the populations of the barn owl and kestrel, that "the available evidence suggests that dieldrin was responsible".

Many factors operate on the populations of birds of prey, including the activities of gamekeepers and others. There is little doubt that gamekeeping helped to cause the drastic decline of many species in the nineteenth and early twentieth centuries, or that a lessening of these activities after that led to some improvement until the early 1950s. The declines mentioned by the Wilson Committee, and attributed by them to dieldrin, occurred from 1955 onwards. In the case of the peregrine falcon, the striking fact is that populations were generally maintained despite the attentions of gamekeepers, egg collectors and falconers even in such hard pressed areas as the coast of Sussex, until the arrival of persistent pesticides. Then both numbers and breeding success declined. Since the withdrawal of dieldrin sheep dips, breeding success has improved, as the Wilson Committee noted. So has the peregrine population, although there has been little recovery yet in Wales and southern England, despite an apparent surplus of young being produced elsewhere in Britain. As Ratcliffe $^{4}$ added, the reasons could be complex. The increase in gamekeeping in the $1960 \mathrm{~s}$, accompanied in some cases by the now illegal slaughter of predatory birds, may be one of the factors affecting the recovery of the peregrine, though it does not explain the observed declines in fertility. The impact, however, is probably more severe, especially in southern England, on other species of birds of prey.

\section{Yours faithfully, STanley Cramp}

The Birds of the Western Palearctic,

32 Queen Court,

London $W C 1 N 3 B B$

${ }^{1}$ Hickey, J. J., Peregrine Falcon Populations (University of Wisconsin Press, 1969).

${ }^{2}$ Ratcliffe, D. A., J. Appl. Ecol., 7, 67-115 (1970).

${ }^{3}$ Advisory Committee on Pesticides and other Toxic Chemicals, 148 (HMSO, 1969).

${ }^{4}$ Ratcliffe, D. A., BTO News, 49, 1 (1972).

\section{Announcements}

\section{University News}

Professor Daniel Branton, University of California, Berkeley, has been appointed professor of biology at Harvard University.

The personal title of professor of geology has been conferred on Dr John R. L. Allen, University of Reading.

\section{Appointments}

Professor Colin Robinson, University of Surrey, has been appointed a member of the Electricity Supply Research Council.
Dr Eric Eastwood, director of research of the General Electric Company, and chief scientist of the Marconi Company Limited, has been appointed president of the Institution of Electrical Engineers.

\section{Miscellaneous}

The Priestley Medal of the American Chemical Society has been awarded to Professor Harold Urey, University of California.

The Meldola Medal of the Royal Institute of Chemistry has been awarded jointly to Professor G. M. Bancroft, University of Western Ontario, and Dr J. F. Kennedy, University of Birmingham.
Dr Zeilig Rabinowitz and Dr Richard Hornreich have been awarded the Sarah Zinder Leedy award for outstanding work carried out at the Weizmann Institute of Science.

The Lunar Science Institute, Houston, Texas, is attempting to build a data information bank, relating to lunar studies since 1950. Contributions, in the form of reprints, reports, photographs, maps and so on, are requested by the Institute. Material, and inquiries, should be addressed to Moon Literature Project, The Lunar Science Institute Library, 3303 NASA Road 1, Houston, Texas 77058, USA. 